\title{
Statistical Analysis of Loss of Offsite Power Events
}

\author{
Andrija Volkanovski, Antonio Ballesteros Avila, and Miguel Peinador Veira \\ European Commission, Joint Research Centre, Institute for Energy and Transport, P.O. Box 2, 1755 ZG Petten, Netherlands
}

Correspondence should be addressed to Andrija Volkanovski; andrija.volkanovski@ec.europa.eu

Received 7 January 2016; Accepted 20 March 2016

Academic Editor: Tomasz Kozlowski

Copyright (C) 2016 Andrija Volkanovski et al. This is an open access article distributed under the Creative Commons Attribution License, which permits unrestricted use, distribution, and reproduction in any medium, provided the original work is properly cited.

\begin{abstract}
This paper presents the results of the statistical analysis of the loss of offsite power events (LOOP) registered in four reviewed databases. The reviewed databases include the IRSN (Institut de Radioprotection et de Sûreté Nucléaire) SAPIDE database and the GRS (Gesellschaft für Anlagen- und Reaktorsicherheit mbH) VERA database reviewed over the period from 1992 to 2011. The US NRC (Nuclear Regulatory Commission) Licensee Event Reports (LERs) database and the IAEA International Reporting System (IRS) database were screened for relevant events registered over the period from 1990 to 2013. The number of LOOP events in each year in the analysed period and mode of operation are assessed during the screening. The LOOP frequencies obtained for the French and German nuclear power plants (NPPs) during critical operation are of the same order of magnitude with the plant related events as a dominant contributor. A frequency of one LOOP event per shutdown year is obtained for German NPPs in shutdown mode of operation. For the US NPPs, the obtained LOOP frequency for critical and shutdown mode is comparable to the one assessed in NUREG/CR-6890. Decreasing trend is obtained for the LOOP events registered in three databases (IRSN, GRS, and NRC).
\end{abstract}

\section{Introduction}

The safety systems of the currently operating nuclear power plants are mainly active requiring electrical energy for their activation and operation. The concepts of redundancy, physical separation, and functional independence are applied in the design of the electrical systems in order to achieve the required level of reliability [1].

The loss of offsite power (LOOP) initiating event occurs when all electrical power to the plant from offsite power system is lost. The NPP offsite power system is the transmission power system where the nuclear power plant is connected.

The electrical power after the LOOP is expected to be provided either by the plant generator or, in case of unsuccessful throttle down to house load, by the emergency diesel generators (EDG).

Loss of alternating current (AC) to the essential and nonessential switchgear buses in a NPP (i.e., loss of offsite electric power system concurrent with turbine trip and unavailability of the onsite emergency AC power system) is referred to as a station blackout (SBO). Station blackout does not include the loss of available AC power to buses fed by station batteries through inverters or by the alternate $\mathrm{AC}$ sources.
Deterministic and probabilistic safety analyses $[2,3]$ show that LOOP and consequential SBO are important contributors to NPP safety. The frequency of the LOOP event and the probability of restoration of the offsite power after a given time are important inputs for safety analyses.

Results of the statistical analysis of LOOP events identified in four databases are presented. The description of the databases screening methodology is given in Section 2. The description of the LOOP frequency assessment methodology is detailed in Section 3 with description of the methodology used for trend analysis in Section 4. The obtained LOOP frequencies are presented in Section 5.1. Distributions of the identified LOOP events are given in Section 5.2. The obtained results of the trend analysis are presented in Section 5.3. Main conclusions of the analysis are given in Section 6.

\section{Databases Screening and Identification of Relevant Events}

The four databases of operational events screened in this study for LOOP events are the database "Support a l'Analyse des Problemes, Incidents et Difficultes d'Exploitation" (SAPIDE), owned and managed by IRSN, the database 
"Vertiefte Auswertung meldepflichtiger Ereignisse" (VERA), owned and managed by GRS, the US NRC Licensee Event Report (LER) database, and the IAEA Incident Reporting System (IRS) database [4]. Identification of the relevant LOOP events in the analysed databases was performed in two steps:

(1) First, the databases were searched to identify potential events for consideration.

(2) Search results were reviewed with selection and classification of the relevant events.

Database searching was done with relevant "guidewords" and "keywords" identified in relation to the "LOOP" topic. All identified events in the search of the databases were analysed. The relevant events were selected and classified based on predefined criteria. The methodology for events screening and selection was also applied for analysis of the EDG failures presented in [5].

The database SAPIDE and the database VERA were screened for relevant events reported in the period from January 1, 1992, to December 31, 2011. Different reporting criteria are used in France and Germany, resulting in different type of events to be reported and inserted in the databases. 228 LOOP events from the SAPIDE database and 190 from VERA were selected as relevant for the analysis.

The US NRC LERs database and the IAEA IRS [4] database were searched to identify representative LOOP related events for the period 1990-2012. In total, 120 LOOP events were identified from the US NRC LERs database as relevant for the analysis. The widespread grid disturbance which occurred on August 14, 2003, affecting nine NPPs sites with eleven reactors, was also taken into account. Five of those events were selected and considered further in the analysis. From IAEA IRS database, 52 events were identified as relevant.

Table 1 shows the number of events identified in the analysed databases for different plant status.

Table 1 shows that the largest number of LOOP events is registered during power operation followed by cold shutdown. Different reporting criteria are used in the analysed databases. For example, the hot standby mode is classified in French SAPIDE database in on-power events while in German VERA is classified within hot shutdown mode.

From Table 1, it is apparent that very few LOOP events are reported in IRS. Indeed, IRS includes all reactors in the world and thus also France, German, and US, and hence the number of events should be higher than the sum of these three countries. It can be concluded that LOOP events are not, in general, reported to IRS and hence calculating the LOOP frequency with methodology presented in Section 3 is not meaningful in the case of the LOOP events in IRS.

The need for harmonization and unification of the reporting criteria and events description has been identified in the analysis of the identified events.

\section{LOOP Frequency Assessment Methodology}

Several studies have analysed data on LOOP and offsite power restoration times. The first topic report [6] summarized the results of the technical evaluations done until 1988 and assessed major contributors to the frequency of station blackout. The following two reports document a similar study with primary objective to update the LOOP model parameters, frequency and recovery time, using US power plant event data over the periods of 1980-1996 [7] and 19871995 [8]. The following report [9] includes results of statistical and engineering analysis of LOOP frequencies and durations at commercial nuclear reactors in the US from 1986 to 2012 for both critical (at power) and shutdown operations.

In NUREG/CR-6890 [10], the LOOP events are classified based on the operating state of the plant at the time of the LOOP events. The LOOP events in NUREG/CR-6890 are subdivided into four types by cause or location: plantcentered, switchyard-centered, grid-related, and weatherrelated.

The plant-centered LOOP events include events in which the design and operational characteristics of the nuclear power plant unit are the main cause of the loss of offsite power. Switchyard-centered LOOP events are events in which the equipment, or human-induced failures of equipment, in the switchyard plays the major role in the loss of offsite power. The LOOP events in which the initial failure occurs in the interconnected transmission grid that is outside the direct control of plant personnel are included in grid-related LOOP events. Weather-related LOOP events include LOOP event caused by severe or extreme weather with forceful and nonlocalized effects.

In this paper, the same classification and categories as the ones in NUREG/CR-6890 [10] are used.

The events identified in Table 1 are classified into the LOOP categories based on the categorization given in Table 2.

The total LOOP initiator frequency per reactor critical year is calculated as follows:

$$
f_{\text {LOOP-At-Power }}=\frac{\# \text { of applicable LOOP events }}{\text { Rx critical years }} \text {, }
$$

where \# of applicable LOOP events is the sum of the events within the same category registered in a given period and $\mathrm{Rx}$ critical years are the sum of the reactor critical years of the operating units in the analysed period.

The LOOP initiator frequency per reactor shutdown year is calculated as follows:

$$
f_{\text {LOOP-Shutdown }}=\frac{\# \text { of applicable LOOP events }}{\text { Rx shutdown years }} \text {, }
$$

where \# of applicable LOOP events is the sum of the events within the same category registered in a given period and $\mathrm{Rx}$ shutdown years are the sum of the reactor shutdown years of the operating units in the analysed period.

The assessment of the LOOP frequency, as shown by (1) and (2), requires as input the total reactor critical or shutdown years in the analysed period. The reactor critical and shutdown years are calculated from the number of the operating NPP units in the analysed country in each year for 
TABLE 1: Number of selected events for different plant status and database.

\begin{tabular}{lcccc}
\hline Plant status/database & & Number of events & \\
& SAPIDE-IRSN & VERA-GRS & LER-NRC & 76 \\
On-power & 145 & 102 & 7 & 47 \\
Hot shutdown & 25 & 12 & 37 & 0 \\
Cold shutdown & 58 & 76 & 5 \\
\hline
\end{tabular}

TABLE 2: Categorization of plant status into operational mode.

\begin{tabular}{lc}
\hline Mode & Plant status \\
\hline Critical operation & On-power \\
Shutdown operation & Hot/cold shutdown \\
\hline
\end{tabular}

the analysed period and from the average operating factors (OF):

$$
\mathrm{Rx} \text { critical years }=\mathrm{OF} * \# \text { of operating units, }
$$

$\mathrm{Rx}$ shutdown years $=(1-\mathrm{OF})$

$$
\text { * \# of operating units. }
$$

The operating factor, expressed in percent, is defined as follows:

$$
\mathrm{OF}=\frac{\text { Online hours }}{\text { Total hours }}
$$

The number of the operating units in each year for the analysed period is determined from the data provided in the IAEA Country Nuclear Power Profiles website [11]. The average operating factor of the units is assessed from the Country Nuclear Power Profiles given in the IAEA Power Reactor Information System [12] as weighted average for the analysed period. The number of the operating reactors in the given year and the average operating factor (OF) for the analysed period for each country and database are shown in Tables 3, 4, and 5. The first column in these tables specifies the year with the number of operating units given in second column. The third and fourth columns include the reactor critical and shutdown years. The sums of the reactor critical and shutdown years for the total analysed period are given in the last row of the tables.

\section{Trend Analysis Methodology}

Accident statistics are used extensively for risk analysis of different types of accidents [13, 14]. One of the tools used within accident statistics is statistical trend analysis. The goal of a trend analysis is to investigate whether a trend is present in the data and if the data show an increase or decrease over time.

In classical statistical theory, there are a number of tests for identification of the data trends. In those tests, a typical approach is to assume that the data are realisations of Poisson distributed random variables with an expected value that, if there is a trend, may be different from year to year. A statistical hypothesis test is then used to check if the expected value is
TABLE 3: Critical and shutdown years assessed for IRSN database.

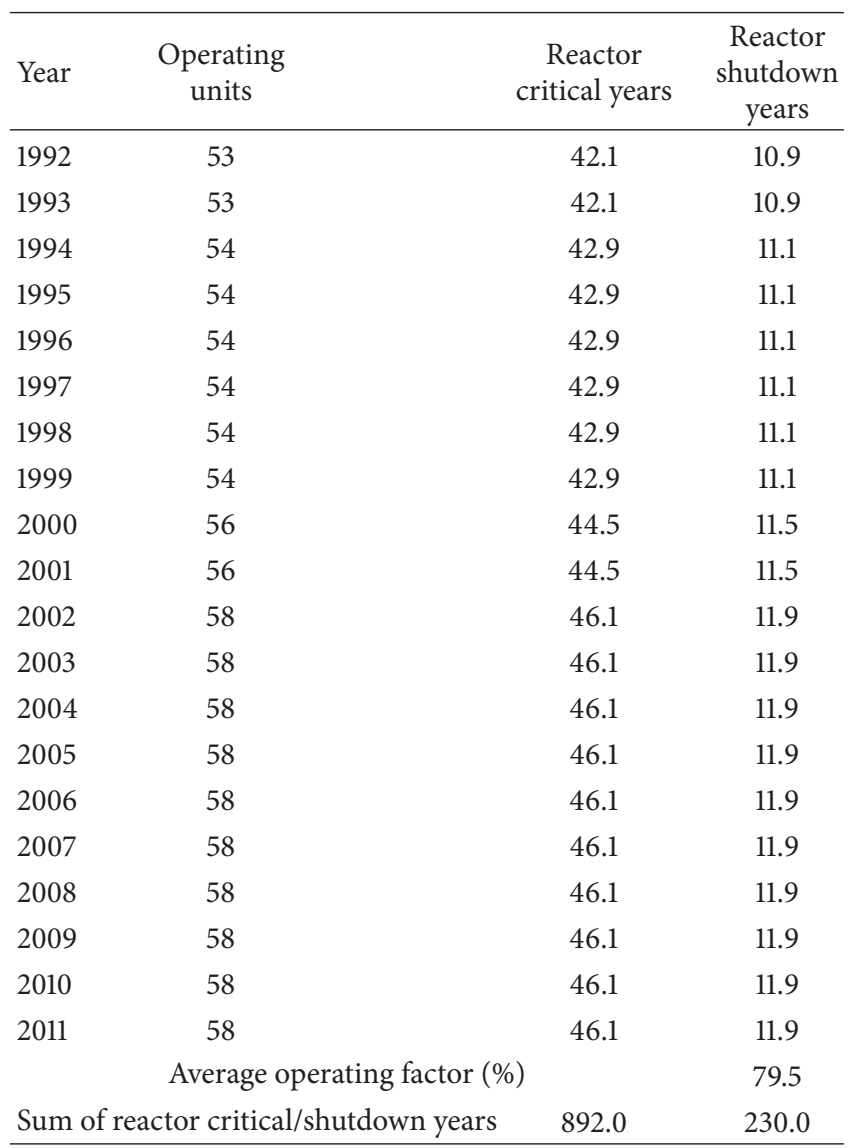

varying from year to year [15-17]. Considerable amount of data or a strong tendency in the data is required in order to apply the classical approach.

The alternative approach for the trend analysis is the utilization of the predictive Bayesian approach $[18,19]$.

In this study, a trend analysis of the identified events is performed with the application of approach presented in [20]. In this approach, focus is on observable quantities, and probability distributions are only used for expressing epistemic uncertainties. Four measures of data trends are introduced in the methodology as described in [20].

The $T_{1}$ measure compares averages of different parts of the data and is given in the following:

$$
T_{1}=\sum_{j=1}^{r-1}\left(\frac{\sum_{i=1}^{j} x_{i}}{j}-\frac{\sum_{i=j+1}^{r} x_{i}}{r-j}\right),
$$


TABLE 4: Critical and shutdown years assessed for GRS database.

\begin{tabular}{lccc}
\hline Year & $\begin{array}{c}\text { Operating } \\
\text { units }\end{array}$ & $\begin{array}{c}\text { Reactor } \\
\text { critical years }\end{array}$ & $\begin{array}{c}\text { Reactor } \\
\text { shutdown } \\
\text { years }\end{array}$ \\
\hline 1992 & 20 & 16.9 & 3.1 \\
1993 & 20 & 16.9 & 3.1 \\
1994 & 19 & 16.1 & 2.9 \\
1995 & 19 & 16.1 & 2.9 \\
1996 & 19 & 16.1 & 2.9 \\
1997 & 19 & 16.1 & 2.9 \\
1998 & 19 & 16.1 & 2.9 \\
1999 & 19 & 16.1 & 2.9 \\
2000 & 19 & 16.1 & 2.9 \\
2001 & 19 & 16.1 & 2.9 \\
2002 & 19 & 16.1 & 2.9 \\
2003 & 18 & 15.2 & 2.8 \\
2004 & 18 & 15.2 & 2.8 \\
2005 & 17 & 14.4 & 2.6 \\
2006 & 17 & 14.4 & 2.6 \\
2007 & 17 & 14.4 & 2.6 \\
2008 & 17 & 14.4 & 2.6 \\
2009 & 17 & 14.4 & 2.6 \\
2010 & 17 & 14.4 & 2.6 \\
2011 & 9 & 7.6 & 1.4 \\
Sum of reactor critical/shutdown years & 303.0 & 84.6 \\
\hline & & & 55.0 \\
\hline
\end{tabular}

where $T_{1}$ is the trend measure, $x_{i}$ is the number of LOOP events in year $i$, and $r$ is the number of analysed years.

Positive $T_{1}$ indicates a decreasing trend of the observed data while a negative value indicates an increasing trend. Larger absolute values of obtained $T_{1}$ mean clearer trend in analysed data.

The $T_{2}$ measure compares the sum of the first half of chronologically ordered data to the sum of the second half:

$$
T_{2}= \begin{cases}\frac{\sum_{i=1}^{r / 2} x_{i}}{r / 2}-\frac{\sum_{i=r / 2+1}^{r} x_{i}}{r-j}, & r \text { even } \\ \frac{\sum_{i=1}^{(r+1) / 2} x_{i}}{(r+1) / 2}-\frac{\sum_{i=(r+1) / 2+1}^{r} x_{i}}{(r-1) / 2}, & r \text { odd }\end{cases}
$$

Positive $T_{2}$, the same as $T_{1}$ measure, indicates decreasing trend in data.

The $T_{3}$ measure is utilized for identification of the nonmonotonic trends and is defined as follows:

$$
T_{3}=\sum_{j=1}^{r-1}\left(\frac{\sum_{i=1}^{j} x_{i}}{j}-\frac{\sum_{i=j+1}^{r} x_{i}}{r-j}\right)^{2} .
$$

The $T_{4}$ measure compares the observation with the mean value and is defined as follows:

$$
T_{4}=\sum_{i=1}^{r}\left(x_{i}-\bar{x}\right)^{2} .
$$

TABLE 5: Critical and shutdown years assessed for US NRC database.

\begin{tabular}{lccc}
\hline Year & $\begin{array}{c}\text { Operating } \\
\text { units }\end{array}$ & $\begin{array}{c}\text { Reactor } \\
\text { critical years }\end{array}$ & $\begin{array}{c}\text { Reactor } \\
\text { shutdown } \\
\text { years }\end{array}$ \\
\hline 1990 & 110 & 93.5 & 16.5 \\
1991 & 109 & 92.6 & 16.4 \\
1992 & 109 & 92.6 & 16.4 \\
1993 & 109 & 92.6 & 16.4 \\
1994 & 110 & 93.5 & 16.5 \\
1995 & 109 & 92.6 & 16.4 \\
1996 & 107 & 90.9 & 16.1 \\
1997 & 104 & 88.4 & 15.6 \\
1998 & 104 & 88.4 & 15.6 \\
1999 & 104 & 88.4 & 15.6 \\
2000 & 104 & 88.4 & 15.6 \\
2001 & 104 & 88.4 & 15.6 \\
2002 & 104 & 88.4 & 15.6 \\
2003 & 104 & 88.4 & 15.6 \\
2004 & 104 & 88.4 & 15.6 \\
2005 & 104 & 88.4 & 15.6 \\
2006 & 104 & 88.4 & 15.6 \\
2007 & 104 & 88.4 & 15.6 \\
2008 & 104 & 88.4 & 15.6 \\
2009 & 104 & 88.4 & 15.6 \\
2010 & 104 & 88.4 & 15.6 \\
2011 & 104 & 88.4 & 15.6 \\
2012 & 104 & 88.4 & 15.6 \\
& Average operating factor $(\%)$ & & 84.9 \\
\hline & & 2062.0 & 365.0 \\
\hline
\end{tabular}

Larger $T_{4}$ measure indicates larger absolute differences of the analysed observations, both positive and negative, from the mean value.

These trend measures are calculated for LOOP events registered in each database over the analysed period. The next step is to generate new datasets $x_{1}^{*}, \ldots, x_{r}^{*}$ from the original data and assess trend measures for the new datasets. The new datasets are generated from the Poisson uncertainty distribution conditionally on the number of events to be equal to the identified one in data shown by (10) and equal average given with (11). Consider

$$
\begin{aligned}
& n=\sum_{i=1}^{r} x_{i}^{*}, \\
& \bar{x}=\sum_{i=1}^{r} \frac{x_{i}}{r} .
\end{aligned}
$$

The new datasets should have the sum of the LOOP events equal to the sum in original data and their mean should be equal to the mean calculated for calculated data. Generating $r$ new datasets $x_{1}^{*}, \ldots, x_{r}^{*}$ is done with the utilization of multinomial distribution with $r$ outcomes of equal probability $1 / r$ 
TABLE 6: Plant-level LOOP frequencies assessed from IRSN database.

\begin{tabular}{|c|c|c|c|c|}
\hline Mode & LOOP category & Number of events & Mean frequency & Frequency units \\
\hline Critical operation & Plant & 110 & $1.23 E-01$ & /rcry \\
\hline Critical operation & Switchyard & 26 & $2.91 E-02$ & /rcry \\
\hline Critical operation & Grid & 3 & $3.36 E-03$ & /rcry \\
\hline Critical operation & Weather & 6 & $6.73 E-03$ & /rcry \\
\hline Critical operation & All & 145 & $1.63 E-01$ & /rcry \\
\hline Shutdown operation & Plant & 71 & $3.09 E-01$ & /rsy \\
\hline Shutdown operation & Switchyard & 11 & $4.78 E-02$ & /rsy \\
\hline Shutdown operation & Grid & 1 & $4.35 E-03$ & /rsy \\
\hline Shutdown operation & Weather & 0 & 0 & /rsy \\
\hline Shutdown operation & All & 83 & $3.61 E-01$ & /rsy \\
\hline
\end{tabular}

TABLE 7: Plant-level LOOP frequencies assessed from GRS database.

\begin{tabular}{|c|c|c|c|c|}
\hline Mode & LOOP category & Number of events & Mean frequency & Frequency units \\
\hline Critical operation & Plant & 81 & $2.67 E-01$ & /rcry \\
\hline Critical operation & Switchyard & 2 & $6.60 E-03$ & /rcry \\
\hline Critical operation & Grid & 16 & $5.28 E-02$ & /rcry \\
\hline Critical operation & Weather & 3 & $9.90 E-03$ & /rcry \\
\hline Critical operation & All & 102 & $3.37 E-01$ & /rcry \\
\hline Shutdown operation & Plant & 75 & $1.36 E+00$ & /rsy \\
\hline Shutdown operation & Switchyard & 1 & $1.82 E-02$ & /rsy \\
\hline Shutdown operation & Grid & 9 & $1.64 E-01$ & /rsy \\
\hline Shutdown operation & Weather & 3 & $5.46 E-02$ & /rsy \\
\hline Shutdown operation & All & 88 & $1.60 E+00$ & /rsy \\
\hline
\end{tabular}

and with the number of trials equal to $n$ as defined by (10) and given in [20]. The routine RNMTN from Fortran Numerical Stat Library $[21,22]$ is utilized for the generation of the new datasets.

For each of these datasets, the values of trend measures $T$ are calculated and compared with the observed value of $T$ from the original data. If the observed value of $T$ measure from the original data is among the largest or smallest predefined percentage (e.g., 5-10\%) of the values of the generated data, it is concluded that there is a trend in the original data.

The trend measures are calculated for events registered during power and shutdown operation for the sum of LOOP events in the given year. In total $r=10000$ new datasets are generated and trend parameters are determined. The generated trend parameters are compared to the calculated ones. The obtained results are given in Section 5.

\section{Results}

The results of the analysis of the identified LOOP events are given in the following sections. The obtained LOOP frequencies for different events categories are given in Section 5.1. The distribution of the identified events in the analysed period is given in Section 5.2, with the results of the trend analysis in Section 5.3.
5.1. Obtained LOOP Frequency. The obtained LOOP frequencies for the three analysed databases are given in Tables 6-8. The first column of the tables defines the plant operational mode (critical/shutdown) with LOOP categories given in the second column. The number of identified events for each category and mode is given in third column. The mean frequency of the LOOP events per reactor critical year (rcry) or reactor shutdown year (rsy) is given in the fourth column. The LOOP frequency is obtained from (1) and (2) for power and shutdown operation as described in Section 3.

The LOOP frequencies obtained for the French and German NPPs during critical operation, as shown in Tables 6 and 7, are of the same order of magnitude. The frequencies of the LOOP events are twice larger for German plants compared to the French NPPs. Tables 6 and 7 show that plant related events are the dominant contributors to the LOOP events in the IRSN and GRS databases.

The difference of the assessed LOOP frequencies, between the French and German NPPs, is even larger for shutdown operations. A frequency of at least one LOOP per shutdown year is obtained for the German nuclear power plants. This partly can be attributed to the reporting criteria together with the different structures of NPP's fleets and a higher amount of operating NPPs in France. No data from previous studies was available for comparison of obtained mean frequencies given in Tables 6 and 7. 
TABLE 8: Plant-level LOOP frequencies assessed from US NRC database.

\begin{tabular}{|c|c|c|c|c|}
\hline Mode & LOOP category & Number of events & Mean frequency & Frequency units \\
\hline Critical operation & Plant & 14 & $6.79 E-03$ & /rcry \\
\hline Critical operation & Switchyard & 42 & $2.04 E-02$ & /rcry \\
\hline Critical operation & Grid & 7 & $3.39 E-03$ & /rcry \\
\hline Critical operation & Weather & 12 & $5.82 E-03$ & /rcry \\
\hline Critical operation & All & 75 & $3.64 E-02$ & /rcry \\
\hline Shutdown operation & Plant & 13 & $3.56 E-02$ & /rsy \\
\hline Shutdown operation & Switchyard & 23 & $6.30 E-02$ & /rsy \\
\hline Shutdown operation & Grid & 4 & $1.10 E-02$ & /rsy \\
\hline Shutdown operation & Weather & 5 & $1.37 E-02$ & /rsy \\
\hline Shutdown operation & All & 45 & $1.23 E-01$ & /rsy \\
\hline
\end{tabular}

Results obtained for the event in US LER database are given in Table 8.

For LOOP frequency during critical operation, a value of $3.64 E-02 /$ rcry is calculated for the US NPPs, as indicated in Table 8 , which is comparable to the frequency $3.59 E-2 /$ rcry assessed in NUREG/CR-6890 [10]. The LOOP frequency of $1.23 E-01 /$ rsy obtained for shutdown operation is also comparable to the frequency of $1.96 E-1 /$ rsy in NUREG/CR6890 [10]. The smaller value of the grid-related events during critical operation in Table 8 can be attributed to the consideration of selected events in the analysis.

The results in Tables 6-8 show that obtained LOOP frequencies during shutdown operation are larger compared to obtained LOOP frequencies for critical operation.

The maintenance activities on the electrical systems of the NPP in the largest extent are done during shutdown mode of operation. The electrical equipment and systems are removed for test, inspection, and maintenance during outage resulting in decreased redundancy of the NPP electrical system and increased susceptibility to LOOP events. Assessed LOOP frequencies during critical and shutdown operation are given in per year frequency unit. The longest period of shutdown operation of the NPP is in most cases during the refuelling outage which generally is shorter compared to the critical operation.

5.2. Distribution of the Events. Figures 1 and 2 show the distribution of events per unit in given year in the primary axis and the number of operating units in the secondary axis for the French IRSN and German GRS databases, respectively.

An average rate of 0.2 events per unit in year is obtained for the French NPPs and 0.53 events for the German plants.

Figure 3 shows the distribution of events registered in the US NRC database.

The number of the reported events normalized to the number of units in US, as shown in Figure 3, is one order of magnitude smaller compared to the events registered in Germany and France. The plant related LOOP events are dominant contributors to the events registered in France and Germany. The switchyard failures are dominant contributors to the events registered in US. This indicates that larger number of registered events for French and German plants

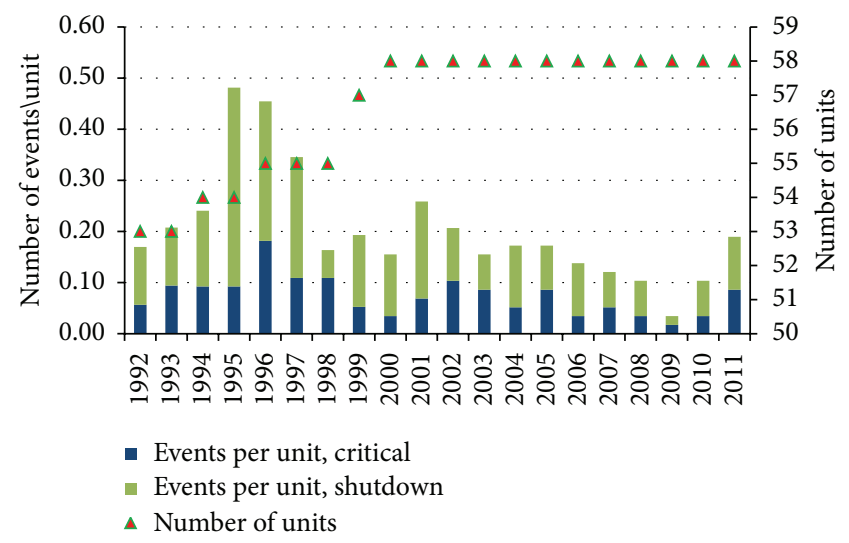

FIgURE 1: Distribution of events at French units.

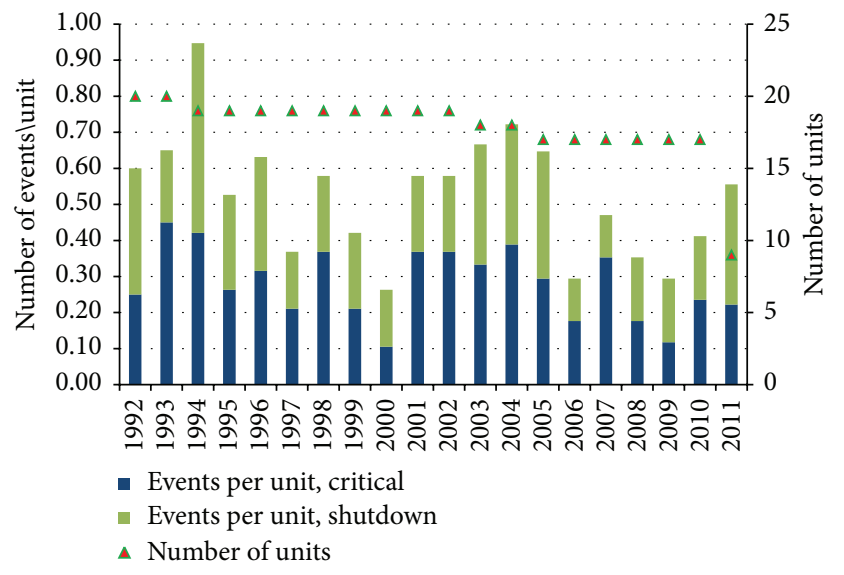

Figure 2: Distribution of events at German units.

can be attributed to the plant specifics including power system design and maintenance policies.

The distribution of the events registered in IAEA IRS database is given in Figure 4.

5.3. Trend Analysis. The results of the trend analysis are given in Tables 9, 10, 11, and 12. The first column defines the mode of operation, with the trend measure and obtained 


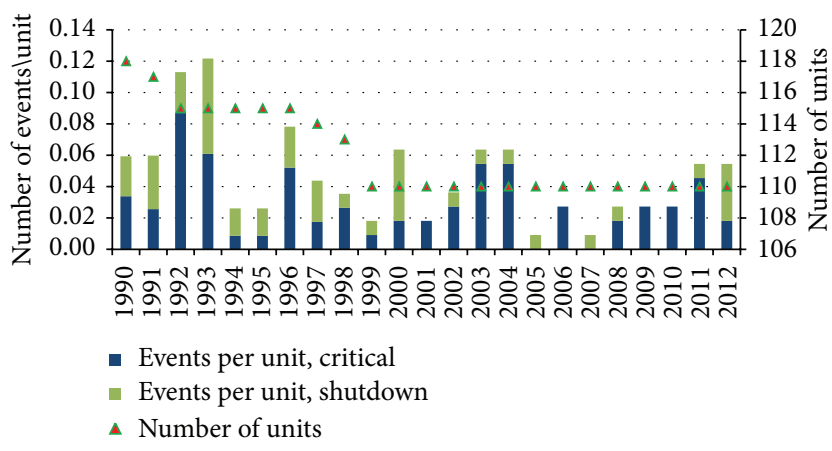

Figure 3: Distribution of events in the US NRC LERs database.

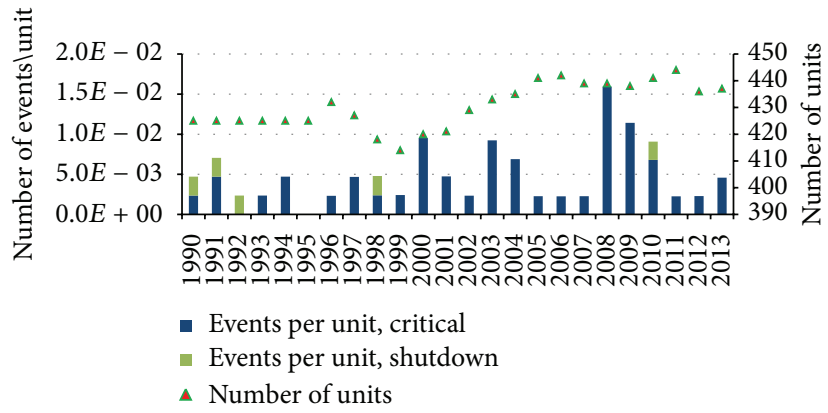

FIGURE 4: Distribution of events in the IAEA IRS database.

value given in second and third column. The percentage of the trend measures obtained from the generated datasets that are smaller (in case of positive measure) or larger (in case of negative measure) than the analytically assessed measure is given in last column. These percentages indicate the confidence level of the assessed trend in the analysed data.

Table 9 shows the results obtained for the events registered in the IRSN database. The positive $T_{1}$ for all three modes (critical, shutdown, and combined events) indicates a decreasing trend in the LOOP data. A large percentage of generated datasets have a smaller value than the measured value obtained from the original data, indicating that there is a trend in the analysed data. The smaller percentage of $T_{4}$ for shutdown mode indicates large deviations compared to the mean value of events in analysed period. This result is expected considering the large number of registered events in year 1996, as shown in Figure 1.

A decreasing trend is also identified for events from the GRS database for all modes of operation, as shown by the results given in Table 10. Small percentage is obtained for $T_{4}$ resulting from large deviations of observations in years 1994 and 2000 compared to the mean value, as shown in Figure 2.

A decreasing trend is also identified for events registered in the US NRC LER database as shown in Table 11. The last column in Table 11 shows that the calculated measures are within the $10 \%$ of the largest values obtained from the simulation. The only exceptions are the $T_{2}$ and $T_{3}$ measures assessed for critical operation. A large difference between events registered in the first and second half of analysed period is indicated by the smaller confidence level obtained
TABLE 9: Trend parameters for IRSN database.

\begin{tabular}{lccc}
\hline Mode & Parameter & Calculated value & $\begin{array}{c}\text { Percentage of smaller/ } \\
\text { larger simulated values }\end{array}$ \\
\hline Critical & $T_{1}$ & 65.7 & $99.94 \%$ \\
Critical & $T_{2}$ & 5.1 & $100.00 \%$ \\
Critical & $T_{3}$ & 320.3 & $99.95 \%$ \\
Critical & $T_{4}$ & 409.8 & $100.00 \%$ \\
Shutdown & $T_{1}$ & 24.9 & $94.84 \%$ \\
Shutdown & $T_{2}$ & 1.5 & $96.12 \%$ \\
Shutdown & $T_{3}$ & 55.3 & $89.74 \%$ \\
Shutdown & $T_{4}$ & 82.6 & $59.19 \%$ \\
Both & $T_{1}$ & 90.6 & $99.99 \%$ \\
Both & $T_{2}$ & 6.6 & $100.00 \%$ \\
Both & $T_{3}$ & 628.0 & $100.00 \%$ \\
Both & $T_{4}$ & 676.8 & $100.00 \%$ \\
\hline
\end{tabular}

TABLE 10: Trend parameters for the GRS database.

\begin{tabular}{lccc}
\hline Mode & Parameter & Calculated value & $\begin{array}{c}\text { Percentage of smaller/ } \\
\text { larger simulated values }\end{array}$ \\
\hline Critical & $T_{1}$ & 37.5 & $98.62 \%$ \\
Critical & $T_{2}$ & 1.2 & $90.17 \%$ \\
Critical & $T_{3}$ & 85.5 & $94.67 \%$ \\
Critical & $T_{4}$ & 81.8 & $32.93 \%$ \\
Shutdown & $T_{1}$ & 35.9 & $98.88 \%$ \\
Shutdown & $T_{2}$ & 1.2 & $91.61 \%$ \\
Shutdown & $T_{3}$ & 73.9 & $94.87 \%$ \\
Shutdown & $T_{4}$ & 72.8 & $39.24 \%$ \\
Both & $T_{1}$ & 73.4 & $99.93 \%$ \\
Both & $T_{2}$ & 2.4 & $96.70 \%$ \\
Both & $T_{3}$ & 301.2 & $99.67 \%$ \\
Both & $T_{4}$ & 235.0 & $83.52 \%$ \\
\hline
\end{tabular}

for $T_{2}$ and $T_{3}$ measures for the events registered during critical operation.

The calculated $T_{1}$ for the events registered during critical operation in the IAEA database given in Table 12 is negative, indicating an increasing trend in the data. The obtained values of the $T_{1}$ and $T_{2}$ measures are within the smallest $10 \%$ of the values assessed from the simulations confirming the increasing trend in the data. The lower confidence level of the $T_{4}$ measure indicates very large deviations of the registered events in the analysed period from their mean value. The positive value of the $T_{1}$ trend measures for events registered during shutdown operation in Table 12 indicates a decreasing trend of LOOP events during shutdown.

The trend of the combined events reported in the IAEA database is increasing. As a result of the differing trends obtained for events registered during critical and shutdown operation, the trend of combined events has small confidence level and therefore it is not possible to confirm/verify the trend in the data. 
TABLE 11: Trend parameters for the US NRC database.

\begin{tabular}{lccc}
\hline Mode & Parameter & Calculated value & $\begin{array}{c}\text { Percentage of smaller/ } \\
\text { larger simulated values }\end{array}$ \\
\hline Critical & $T_{1}$ & 24.1 & $94.86 \%$ \\
Critical & $T_{2}$ & 0.5 & $78.03 \%$ \\
Critical & $T_{3}$ & 43.4 & $88.71 \%$ \\
Critical & $T_{4}$ & 130.4 & $98.72 \%$ \\
Shutdown & $T_{1}$ & 30.1 & $99.65 \%$ \\
Shutdown & $T_{2}$ & 1.8 & $99.97 \%$ \\
Shutdown & $T_{3}$ & 65.1 & $99.64 \%$ \\
Shutdown & $T_{4}$ & 71.0 & $96.95 \%$ \\
Both & $T_{1}$ & 54.1 & $99.83 \%$ \\
Both & $T_{2}$ & 2.3 & $99.47 \%$ \\
Both & $T_{3}$ & 192.1 & $99.82 \%$ \\
Both & $T_{4}$ & 257.9 & $99.91 \%$ \\
\hline
\end{tabular}

TABLE 12: Trend parameters for the IAEA database.

\begin{tabular}{lccc}
\hline Mode & Parameter & Calculated value & $\begin{array}{c}\text { Percentage of smaller/ } \\
\text { larger simulated values }\end{array}$ \\
\hline Critical & $T_{1}$ & -19.6 & $4.56 \%$ \\
Critical & $T_{2}$ & -1.1 & $3.86 \%$ \\
Critical & $T_{3}$ & 25.5 & $88.05 \%$ \\
Critical & $T_{4}$ & 63.0 & $91.86 \%$ \\
Shutdown & $T_{1}$ & 7.41 & $97.47 \%$ \\
Shutdown & $T_{2}$ & 0.25 & $96.91 \%$ \\
Shutdown & $T_{3}$ & 3.91 & $94.72 \%$ \\
Shutdown & $T_{4}$ & 3.96 & $0.00 \%$ \\
Both & $T_{1}$ & -12.16 & $16.10 \%$ \\
Both & $T_{2}$ & -0.83 & $10.55 \%$ \\
Both & $T_{3}$ & 15.54 & $60.19 \%$ \\
Both & $T_{4}$ & 61.33 & $81.98 \%$ \\
\hline
\end{tabular}

Final conclusion from the analysis is that decreasing trend of registered LOOP events is identified in the analysed databases, with the exception of the events registered in IAEA IRS. The analysis of events in the IAEA database showed that different trends are identified during critical and shutdown modes, with no trend observed for the whole set of data.

\section{Conclusions}

This paper presents the results of the statistical analyses of LOOP events registered in four databases of operational events. The reviewed databases are SAPIDE managed by IRSN (Institut de Radioprotection et de Surreté Nucléaire) and VERA by GRS (Gesellschaft für Anlagen- und Reaktorsicherheit $\mathrm{mbH}$ ) over the period from 1992 to 2011. The Nuclear Regulatory Commission (NRC) Licensee Event Reports (LERs) database and the IAEA International Reporting System (IRS) database were also reviewed for relevant events registered in the period from 1990 to 2012.
In total, 228 LOOP relevant events were identified in IRSN SAPIDE, 190 in GRS VERA, 120 in US NRC LERs, and 52 in the IAEA IRS database. These LOOP events were classified considering the mode of operation (critical and shutdown) and by cause or location (plant-centered, switchyard-centered, grid-related, and weather-related).

The statistical analyses of the identified events include assessment of the LOOP frequency, distribution of events in the analysed period, and trend analysis of the events.

Results of the LOOP frequency assessment show that comparable frequency of LOOP events during critical operation was obtained for events in the IRSN SAPIDE and GRS VERA databases. The LOOP events reported in IAEA IRS are not considered as representative for the LOOP frequency assessment and not analysed further.

Plant-centered events are identified as dominant contributors to the LOOP events in both databases. A frequency of at least one LOOP event per shutdown year is obtained for the GRS VERA database. For US NPPs, the obtained LOOP frequency for critical and shutdown operation is comparable to those in previous studies [10]. The switchyard-centered related LOOP events are dominant contributors to the LOOP frequency during critical operation assessed for US NPPs. The obtained LOOP frequency during shutdown mode is larger compared to frequency for critical mode in three analysed databases (IRSN, GRS, and NRC). The obtained result is attributed to the maintenance activities on electrical system during shutdown operation and consequential LOOP events.

Results of the trend analysis show that decreasing trend is obtained for the LOOP events registered in three databases (IRSN, GRS, and NRC). The decreasing trend in these databases was obtained for events registered during critical and shutdown operation as well as combined (sum) events. Different trends were identified during critical and shutdown modes of operation for the LOOP events registered in the IAEA database. Combined events reported during critical and shutdown modes show no trend.

\section{Disclosure}

The scientific output expressed in this paper may not in any circumstances be regarded as stating an official position of the European Commission. Neither the European Commission nor any person acting on behalf of the Commission is responsible for the use which might be made of this publication.

\section{Competing Interests}

The authors declare that they have no competing interests.

\section{Acknowledgments}

This work has been performed by the European Clearinghouse on NPP Operational Experience Feedback at the Institute for Energy and Transport of the Joint Research Centre (JRC/IET) in cooperation with IRSN (Institut de Radioprotection et de Sûreté Nucléaire), France, and GRS (Gesellschaft für Anlagen- und Reaktorsicherheit mbH), Germany. This 
research was supported by the European Commission, DGJRC, Institute for Energy and Transport, Petten, Netherlands, through EURATOM Research Framework Programme. This research was partly supported by the Slovenian Research Agency (Contract no. P2-0026).

\section{References}

[1] A. Volkanovski, "On-site power system reliability of a nuclear power plant after the earthquake," Kerntechnik, vol. 78, no. 2, pp. 99-112, 2013.

[2] A. Volkanovski, Impact of offsite power system reliability on nuclear power plant safety [Ph.D. thesis], University of Ljubljana, Ljubljana, Slovenia, 2008.

[3] A. Volkanovski and A. Prošek, "Extension of station blackout coping capability and implications on nuclear safety," Nuclear Engineering and Design, vol. 255, pp. 16-27, 2013.

[4] IAEA, IRS Guidelines-Joint IAEA/NEA International Reporting System for Operating Experience, Service Series 19, IAEA, Vienna, Austria, 2010.

[5] D. Kančev, A. Duchac, B. Zerger, M. Maqua, and D. Wattrelos, "Statistical analysis of events related to emergency diesel generators failures in the nuclear industry," Nuclear Engineering and Design, vol. 273, pp. 321-331, 2014.

[6] NRC, Evaluation of Station Blackout Accidents at Nuclear Power Plants, U.S. Nuclear Regulatory Commission, 1988.

[7] US Nuclear Regulatory Commission (NRC), Evaluation of Loss of Offsite Power Events at Nuclear Power Plants: 1980-1996, US Nuclear Regulatory Commission (NRC), Rockville, Md, USA, 1998.

[8] NRC, Rates of Initiating Events at U.S. Nuclear Power Plants: 1987-1995, U.S. Nuclear Regulatory Commission, 1999.

[9] EPRI, Losses of Off-Site Power at U.S. Nuclear Power PlantsSummary of Experience Through 2012, Electric Power Research Institute, 2013.

[10] NRC, Ed., Reevaluation of Station Blackout Risk at Nuclear Power Plants, NUREG/CR 6890, NRC, Washington, DC, USA, 2005.

[11] IAEA, "Country Nuclear Power Profiles," 2015, https://cnpp.iaea .org/pages/index.htm.

[12] IAEA, Power Reactor Information System, IAEA, 2015, https:// www.iaea.org/pris/.

[13] M. J. Crowder, A. Kimber, T. Sweeting, and R. Smith, Statistical Analysis of Reliability Data, vol. 27, CRC Press, New York, NY, USA, 1994.

[14] W. Q. Meeker and L. A. Escobar, Statistical Methods for Reliability Data, John Wiley \& Sons, New York, NY, USA, 2014.

[15] E. L. Frome, M. H. Kutner, and J. J. Beauchamp, "Regression analysis of Poisson-distributed data," Journal of the American Statistical Association, vol. 68, pp. 935-940, 1973.

[16] R. Magel and F. Wright, "Tests for and against trends among Poisson intensities," in Inequalities in Statistics and Probability, vol. 5 of Lecture Notes-Monograph Series, pp. 236-243, Institute of Mathematical Statistics, Hayward, Calif, USA, 1984.

[17] K. Krishnamoorthy and J. Thomson, "A more powerful test for comparing two Poisson means," Journal of Statistical Planning and Inference, vol. 119, no. 1, pp. 23-35, 2004.

[18] T. Aven, Foundations of Risk Analysis: A Knowledge and Decision-Oriented Perspective, Wiley-Interscience, 2003.
[19] S. Apeland, T. Aven, and T. Nilsen, "Quantifying uncertainty under a predictive, epistemic approach to risk analysis," Reliability Engineering \& System Safety, vol. 75, no. 1, pp. 93-102, 2002.

[20] J. T. Kvaløy and T. Aven, "An alternative approach to trend analysis in accident data," Reliability Engineering \& System Safety, vol. 90, no. 1, pp. 75-82, 2005.

[21] Intel ${ }^{\circledR}$ Visual Fortran Composer XE 2013 SP1 for Windows, Intel ${ }^{\circledR}$, USA, 2013

[22] R. W. Software, IMSL Fortran Numerical Library 6.0, 2013. 

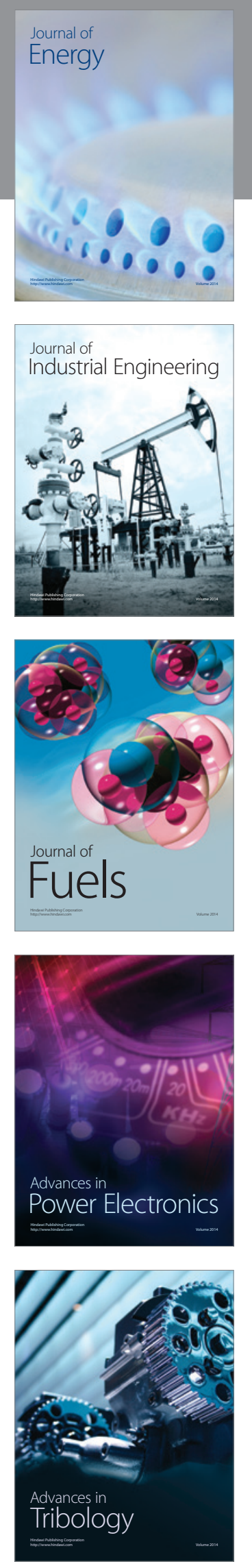
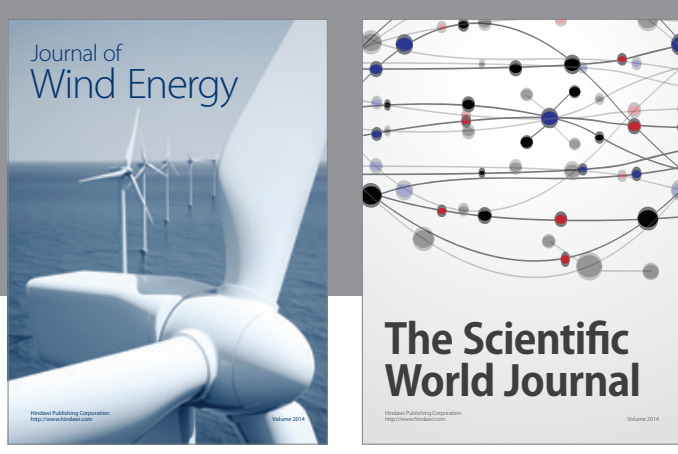

The Scientific World Journal
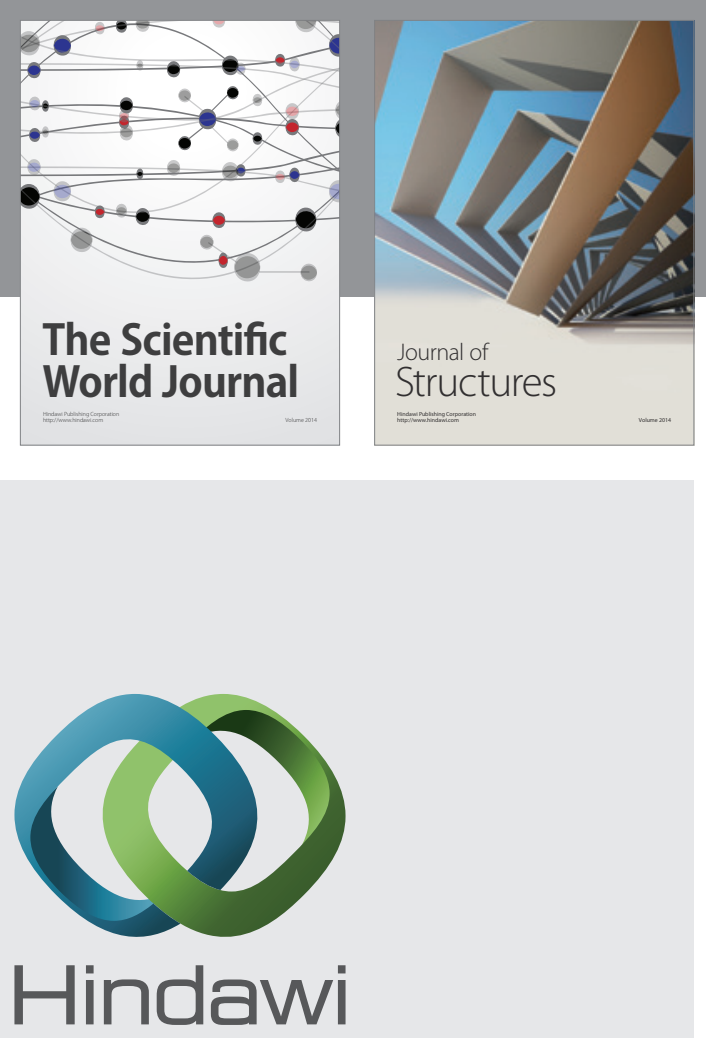

Submit your manuscripts at

http://www.hindawi.com
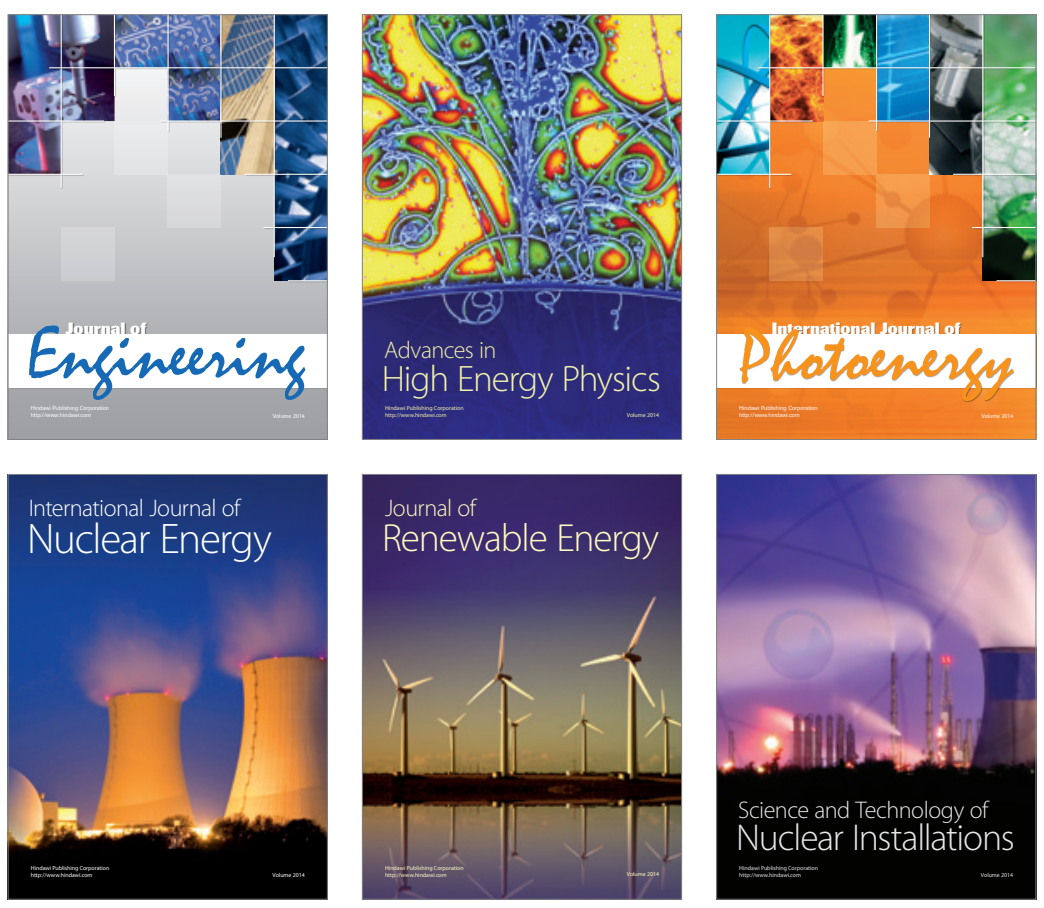
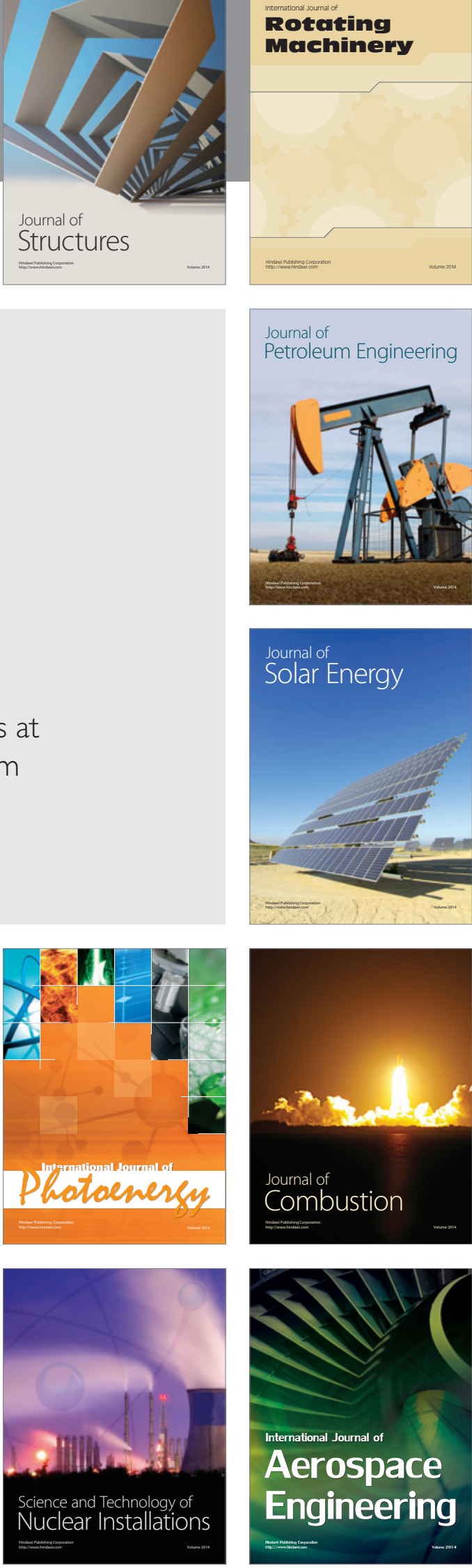